\title{
The Serotonin Reuptake Inhibitor Sertraline Reduces Excessive Alcohol Consumption in Nonhuman Primates: Effect of Stress
}

\author{
J. Higley, Ph.D., M. Hasert, M.S., S. Suomi, Ph.D., and M. Linnoila, M.D., Ph.D.
}

Many monkeys that are reared without adult influence, with only peers, voluntarily consume alcohol in amounts producing intoxication on a relatively regular basis. Using a cross-over design, eight adolescent, peer-reared rhesus monkeys were allowed unfettered access to an $8.4 \%$ ethanol solution and treated with $20 \mathrm{mg} / \mathrm{kg} / 24 \mathrm{~h}$ of sertraline during three phases: home-cage, social separation, and reunion with cage-mates. Although there was no immediate effect, sertraline reduced alcohol consumption beginning the second week of home-cage treatment, but only in subjects that consumed large amounts of alcohol. Initially, the social separation stress caused the sertraline-treated subjects' alcohol consumption rates to return to baseline levels, but when the stress was repeated, alcohol consumption fell below baseline and placebo levels. Sertraline treatment was ineffective in reducing consumption during the stressful period of home-cage reunion, a period characterized by high levels of aggressive behavior. Behaviorally, sertraline reduced aggression and anxiety-like self-directed behaviors. Our findings provide evidence that sertraline may be an effective pharmacological treatment for excessive alcohol consumption and aggression. On the other hand, stress during treatment may reduce sertraline's effectiveness as a treatment for excessive alcohol consumption.

[Neuropsychopharmacology 18:431-443, 1998]

Published by Elsevier Science Inc.
KEY WORDS: Alcoholism and alcohol abuse; Primate; Sertraline; Serotonin; Aggression; Stress

A large number of preclinical studies have reported high rates of alcohol consumption among animals with reduced central nervous system (CNS) serotonin functioning (for reviews, see Sellers et al. 1992; LeMarquand et al. 1994b). Among humans, clinical studies show evidence of reduced CNS serotonin functioning in subjects

From the Section on Neurochemistry and Neuro-endocrinology, Primate Unit, Laboratory of Clinical Studies, Primate Unit, DICBR, NIAAA (JH, MH, ML), and Laboratory of Comparative Ethology, NICHD (SS), Poolesville, Maryland.

Address correspondence to: Dr. J.D. Higley, Laboratory of Clinical Studies, DICBR, NIAAA, Section on Neurochemistry and Neuroendocrinology, Primate Unit, Poolesville, MD 20837.

Received April 23, 1997; revised September 1, 1997; accepted September 3, 1997. at risk for or who exhibit early onset alcohol abuse and alcoholism (for recent reviews see LeMarquand et al. 1994a; Litten et al. 1996; Pettinati 1996). Some recent studies show that selective serotonin reuptake inhibitors (SSRIs) are promising as adjunctive pharmacological treatment for maintenance of abstinence (see LeMarquand et al. 1994b). Preclinical studies with rodents show that the SSRIs reduce alcohol consumption (LeMarquand et al. 1994b). Similarly, in a number of small scale studies, SSRIs have shown promise as an adjunct treatment for alcohol abuse and alcoholism (LeMarquand et al. 1994a; Pettinati 1996). The controlled studies conducted by Gorelick (1989) and Kranzler et al. (1995) showed, however, that fluoxetine was ineffective in promoting maintenance of abstinence among treatment-seeking alcoholics. More recently, researchers used a controlled study to demonstrate that citalopram was efficacious in promoting maintenance 
of abstinence among early-onset, violent male alcoholics thought to have reduced central serotonin functioning (Tiihonen et al. 1996). Because of the conflicting reports on the efficacy of the SSRIs in the maintenance of abstinence, we decided to investigate sertraline as a potential treatment for excessive alcohol intake, using a nonhuman primate model with monkeys known to have reduced central serotonin functioning (Higley et al. 1996d,e). Furthermore, we designed the study specifically to examine the role that stress plays in excessive alcohol consumption among nonhuman primates and to test the efficacy of sertraline in mitigating the effects of stress on alcohol consumption.

Until recently, it was widely believed that nonhuman primates would not voluntarily consume alcohol in appreciable quantities (e.g., Mello and Mendelson 1971; Meisch et al. 1975; Crowley et al. 1983); consequently, they were not typically used in research on alcohol abuse. More recent studies have shown, however, that for many species of primates, many (but not all) subjects will freely consume alcohol in quantities that produce pharmacological effects when an alcohol solution is palatable (Higley et al. 1991; Higley 1996; Higley and Linnoila 1997). Within some species, such as rhesus macaques and other Old World primate species, some individual subjects will routinely consume sufficient quantities of alcohol to produce blood levels exceeding the limits of legal intoxication for most states in the United States, and at times drink amounts that produce stupor and unconsciousness (Erwin et al. 1979; Ervin et al. 1990; Higley et al. 1991). Most rhesus monkeys are modest consumers, however, with only $15-20 \%$ consuming alcohol in daily quantities that produce intoxication.

More recent studies of alcohol consumption in nonhuman primates have investigated variables that are associated with high alcohol consumption. Results from these studies parallel investigations in humans showing that low CSF 5-hydroxyindoleacetic acid (5-HIAA) and 3-methoxy-4-hydroxyphenylgycol (MHPG) are correlated with excessive alcohol consumption (Higley et al. 1991; 1996e). Another factor that increases alcohol consumption in nonhuman primates such as rhesus macaques involves an early rearing history in which young subjects are raised in social groups that do not contain adults (peer-only reared subjects-Higley et al. 1991, 1996e). Subjects reared early in life with only same-aged peers, for example, are about twice as likely to consume alcohol at rates that produce daily intoxication as subjects reared early in life by their parents (Higley et al. 1991, 1996e). Peer-only reared subjects also show low concentrations of CSF 5-HIAA and MHPG (Higley et al. 1991, 1996d,e). Like human subjects with low CSF 5-HIAA concentrations when peer-only reared subjects mature to adulthood, they are excessively aggressive and are more likely to be removed from their social groups for wounds or violent behavior than sub- jects reared by their mothers (Higley et al. 1994; 1996d). Because they share biochemical and behavioral similarities with some types of human alcoholics, and because they are more likely than normally reared monkeys to consume alcohol at rates that produce intoxication, peer-reared monkeys appear to be well suited to evaluate pharmacological treatments for excessive consumption. Based on what is known about peer-only reared subjects, we hypothesized that sertraline would reduce their day-to-day alcohol consumption, particularly during nonstressful home-cage interactions.

Previous studies have suggested that the effect of the SSRIs on alcohol consumption is not uniform across all subjects. For example, Balldin and colleagues (Balldin et al. 1994) found that human subjects with modestly elevated rates of alcohol consumption (below $107 \mathrm{~g}$ per day, mean consumption $85 \mathrm{~g}$ per day) were particularly likely to reduce their alcohol consumption after SSRI treatment as compared with subjects with very high consumption rates (above $107 \mathrm{~g}$, mean consumption 138 g per day). On the other hand, studies show that primates with the lowest CNS serotonin functioning tend to be the highest alcohol consumers (Higley et al. 1991, 1996e), and alcoholics and sons of alcoholics also show low CNS serotonin functioning (Ballenger et al. 1979; Banki 1981; Borg et al. 1985). It is therefore not unreasonable to predict that the subjects with the highest consumption patterns would benefit most from SSRI treatment. Thus, we further hypothesized that sertraline treatment would be most effective in those subjects whose consumption rates were high and whose consumption patterns were less restrained.

Studies have also shown that anxiety-like behaviors and high levels of stress are positively correlated with the level of alcohol consumption (Kraemer and McKinney 1985; Higley et al. 1991, 1996e). Social separation stress (removal and isolation of subjects from their social group) increases alcohol consumption, even among subjects not particularly prone to overconsume alcohol (Kraemer and McKinney 1985; Higley et al. 1991). Among humans who receive antidepressants for the treatment of unipolar depression, some studies show that stress increases probability of relapse (Belsher and Costello 1989; Leverich et al. 1990). Some studies also show that stressful conditions increase the probability of relapse among abstinent alcoholics (Brown et al. 1990), and individuals who relapse after treatment are more likely to report high levels of state and trait anxiety (Brown et al. 1991). Such findings suggest that stress may attenuate the effect of a pharmacological treatment and led us to test the effectiveness of sertraline in peer-reared monkeys under both baseline and stressful conditions. Specifically, we hypothesized that sertraline would reduce alcohol consumption during baseline conditions, but not under conditions of high stress, such as during a social separation and during other challenging social con- 
ditions such as return to a social group after a protracted absence, when rates of physical aggression are high. Some animal studies have shown an immediate reduction in alcohol consumption after treatment with an SSRI (Gulley et al. 1995), but the appearance of sertraline's antidepressant and other treatment effects (e.g., aggression and irritability) is often delayed in time (Guy et al. 1986; Kavoussi et al. 1994). Thus, we assessed alcohol consumption under both acute and chronic sertraline treatment.

\section{METHODS}

\section{Subjects}

The subjects were eight adolescent (mean 52.6, range 52-53 months of age), peer-reared rhesus monkeys $(n=$ 8: four females and four males), all placed, within $24 \mathrm{~h}$ of birth, in the neonatal nursery where they lived in single cages for their first month of life. During this period they received care similar to that described by Blomquist and Harlow (1961). When the youngest subject of each group was 30 days of age, the subjects were placed together into one of two sex-balanced social groups of four, with constant access to the three other same-age monkeys. With the exception of weekly cage cleaning, during which the monkeys were placed as an intact social unit into a smaller cage, and four 1-h separations between 60 and 120 days of age to assess attachment preferences, both groups remained undisturbed in their respective home cages until they were 6 months of age. At that age, they underwent a series of four 4-day social separations. The results of these separation studies have been published elsewhere (Higley et al. 1996d,e). After the separations, the two groups were placed together to form a larger group of eight. All animals received identical treatment prior to and throughout the present experiment.

\section{Procedure}

The experiment utilized a cross-over design with subjects serving as their own controls (see Figure 1). The study consisted of two halves, each of which had four phases: (1) baseline, home-cage interactions, (2) homecage sertraline/placebo treatment, (3) social separation, and (4) recovery. Baseline consisted of 2 weeks of sertraline-free, undisturbed home-cage interactions. The sertraline/placebo treatment phase consisted of 3 weeks of dosing with sertraline or placebo under home cage conditions identical to baseline. Social separation was repeated twice, with each separation and reunion lasting 1 week. The home cage sertraline or placebo recovery phase was identical to the home-cage sertraline/ placebo treatment phase, except it lasted 2 weeks instead of 3. A 3-week washout period was provided before beginning the cross-over half of the study.

The separation phase consisted of two 4-day social separations, each followed by a 3-day home-cage reunion period. During each separation, subjects were removed from their home cage and placed into single cage units where they could hear but not see or touch the other animals. During the first hour of each separation, each animal was removed from its group cage and placed alone in an individual cage where a behavior score was obtained. One hour after separation, a blood sample was obtained, and each subject was returned to its individual cage. This routine was repeated during the second hour. After the behavioral ratings and blood draws, the alcohol-dispensing equipment was set up for each cage, and consumption was recorded for $1 \mathrm{~h}$. Additional daily behavioral ratings were obtained for 5 min each day Tuesday through Friday, and alcohol was dispensed Monday through Thursday. CSF and blood were sampled on Friday in lieu of dispensing alcohol. After recovery from anesthesia for the CSF sampling, the monkeys were returned to their social group for the weekend.

\begin{tabular}{|c|c|c|c|c|c|c|c|c|c|}
\hline \multicolumn{10}{|c|}{ Week of Study } \\
\hline$y=$ & 1 & 2 & 3 & 4 & 5 & 6 & $\overline{7}$ & 8 & 9 \\
\hline & $\begin{array}{r}\text { (No } \\
\text { Placel }\end{array}$ & $\begin{array}{l}\text { line } \\
\text { raline or } \\
\text { lministered) }\end{array}$ & (Sertraline & $\begin{array}{l}\text { Home Cag } \\
\text { r Placebo A }\end{array}$ & Iministrated) & $\begin{array}{r}\text { Se } \\
\text { (Sertrali } \\
\text { Adm }\end{array}$ & $\begin{array}{l}\text { ration } \\
\text { or Placebo } \\
\text { istrated) }\end{array}$ & $\begin{array}{r}\mathbf{R} \\
\text { (Sertralin } \\
\text { Admi }\end{array}$ & $\begin{array}{l}\text { nion } \\
\text { or Placebo } \\
\text { trated) }\end{array}$ \\
\hline $\begin{array}{l}\text { Treat- } \\
\text { ment }\end{array}$ & $\begin{array}{l}\text { Baseline } \\
\text { Week-1 }\end{array}$ & $\begin{array}{l}\text { Baseline } \\
\text { Week-2 }\end{array}$ & $\begin{array}{l}\text { Home Cage } \\
\text { Week-1 }\end{array}$ & $\begin{array}{l}\text { Home Cage } \\
\text { Week-2 }\end{array}$ & $\begin{array}{l}\text { Home Cage } \\
\text { Week-2 }\end{array}$ & $\begin{array}{l}\text { Social } \\
\text { Separation } \\
\text { Week-1 }\end{array}$ & $\begin{array}{l}\text { Social } \\
\text { Separation } \\
\text { Week-2 }\end{array}$ & $\begin{array}{l}\text { Home Cage } \\
\text { Recovery } \\
\text { Week-1 }\end{array}$ & $\begin{array}{l}\text { Home Cage } \\
\text { Recovery } \\
\text { Week-2 }\end{array}$ \\
\hline Placebo & $\begin{array}{l}\text { Baseline } \\
\text { Week-1 }\end{array}$ & $\begin{array}{l}\text { Baseline } \\
\text { Week-2 }\end{array}$ & $\begin{array}{l}\text { Home Cage } \\
\text { Week-1 }\end{array}$ & $\begin{array}{l}\text { Home Cage } \\
\text { Week-2 }\end{array}$ & $\begin{array}{l}\text { Home Cage } \\
\text { Week-3 }\end{array}$ & $\begin{array}{l}\text { Social } \\
\text { Separation } \\
\text { Week-1 }\end{array}$ & $\begin{array}{l}\text { Social } \\
\text { Separation } \\
\text { Week-2 }\end{array}$ & $\begin{array}{l}\text { Home Cage } \\
\text { Reunion } \\
\text { Week-1 }\end{array}$ & $\begin{array}{l}\text { Home Cage } \\
\text { Reunion } \\
\text { Week-2 }\end{array}$ \\
\hline
\end{tabular}

Figure 1. The four experimental phases of the experiment, each lasting 2 or 3 weeks. Alcohol was dispensed during all 9 weeks of the study. Sertraline or placebo was administered in each phase, except for the baseline. The home-cage sertraline administration phase was procedurally identical to the baseline phase, except sertraline was administered each day. Both the baseline and home-cage sertraline administration phases were relatively stress-free, allowing the subjects to interact each day as usual in their home cage. The separation and reunion phases were designed to study the effects of stress on alcohol consumption and sertraline effects. See text for further description. 


\section{Behavior Sampling}

Systematic behavioral recordings were obtained using hand-held portable computers during 5-min blocks for each subject: once daily during home-cage interactions, and twice daily during the four social separations for 5 days a week. Durations and frequencies of behaviors were obtained using an objectively defined 14-category behavioral scoring system (Higley et al. 1992a), specifically designed to assess disturbed behaviors and social functioning in the rhesus monkey. The three observers used in the study to score behaviors were trained by a laboratory technician, who has used the same behavior scoring system for over a decade, to a criterion of $r>$ 0.90 reliability with the technician for all behaviors in the behavioral scoring system.

\section{Dispensing of the Medication}

Sertraline was administered orally, $(20 \mathrm{mg} / \mathrm{kg})$ once each day between 10:00 and 12:00 $\mathrm{h}$. The dosage for the rhesus monkeys was chosen to yield plasma levels similar to the established plasma levels for the treatment of depression in humans (Economics Medical 1966). Pilot data showed that a 30-mg/ $\mathrm{kg}$ dosage produced vomiting in some subjects; thus, a 20-mg dosage was used. To establish that plasma sertraline concentrations were within the clinically relevant range, prior to starting the study, $20 \mathrm{mg} / \mathrm{kg}$ of sertraline was administered to six subjects that were not used in the study and blood was obtained 4 and $24 \mathrm{~h}$ later, with resulting average concentrations of $28.6 / 16.4 \mathrm{ng} / \mathrm{ml}$ $(\mathrm{mn} / \mathrm{sd}) 4 \mathrm{~h}$ later, and $10.0 / 6.7 \mathrm{ng} / \mathrm{ml} 24 \mathrm{~h}$ later. To assure that the subjects' plasma sertraline levels were maintained during the study, steady-state blood samples were obtained $24 \mathrm{~h}$ after dosing at the end of each treatment phase (sertraline concentrations were $83.0 / 29.3 \mathrm{ng} / \mathrm{ml}$ after the first and $64.5 / 13.9 \mathrm{ng} / \mathrm{ml}$ after the second half of the study). The sertraline used in the study was provided courtesy of Pfizer Co. To disguise the taste, sertraline was administered orally in various vehicles, depending on the subjects' individual taste preferences. Examples of the vehicles used were small amounts of chocolate frosting, jellies, mashed bananas (without peels), grapes, apples, and different flavors of commercial baby food.

Subjects were administered their medication each morning by placing them as a group into one of two connected smaller holding cages $(84 \times 84 \times 84 \mathrm{~cm})$. These cages were fastened side by side to the wall in the subjects' larger pen, and connected together via a mesh tunnel $(92 \times 30 \times 41 \mathrm{~cm})$. The mesh tunnel could be closed off at each end with a sliding door. In the middle of the tunnel was a hatch door, which when opened allowed the researchers to hand the subjects the vehiclemedication, and observe them until the vehicle-medication was completely consumed. Subjects reliably consumed over $90 \%$ of the medication using this procedure.
To attenuate any stress that this procedure might engender, 1 month prior to starting the study, the animals were trained daily to enter the cage and take fruit from the researchers. During this time, they were also allowed to drink the aspartame-sweetened vehicle in which the alcohol would be placed for an hour each day.

\section{Alcohol Dispensing}

During each of the sertraline/placebo cross-over halves of the study, subjects were allowed to consume a $8.4 \%$ (volume/volume) ethanol aspartame-sweetened solution for $1 \mathrm{~h}$ a day, 4 days a week (Monday to Thursday), for a total of 11 consecutive weeks before crossing to the other halfmedication or placebo. Alcohol was dispensed in the subjects' home or separation cage. The monkeys received their regular food rations at 11:00 and 14:00 $\mathrm{h}$ and were not food deprived throughout the study. The aspartamesweetened vehicle solution was available when the alcohol was dispensed, thus giving each subject a choice between the alcohol or vehicle. To preclude water satiation, water was withheld during the hour just prior to when the alcohol solution was dispensed. Water was available at all other times, including when alcohol was dispensed.

Rank-dependent differential access to the solutions was precluded by dividing the groups into their original peer groups of four subjects, and placing each group into one of the two smaller cages, described above, where alcohol was freely available. Within each of the two smaller cages were two three-chamber, sideby-side, clear Plexiglas compartments. Each chamber fit one monkey, with an internal perch where an individual subject could enter, still see the other monkeys, but sit and drink without being harassed. The three-chamber, side-by-side Plexiglas units hung on adjacent sides of each smaller cage as two units (sized $46 \times 68 \times 28 \mathrm{~cm}$ ) each divided into three equal-sized chambers $(46 \times$ $22 \times 28 \mathrm{~cm}$ ) in the left and right halves of the smaller cage. The subjects entered a chamber from the bottom and were surrounded on all sides by the clear Plexiglas. The alcohol was dispensed to each chamber using a gravity-fed, self-zeroing burette, connected via plastic tubing, to a lick-initiated stainless steel nipple, identical to the nipple used to dispense water in the home cage.

During nonsocial separation weeks, after the hour of alcohol consumption, the animals were released from the two smaller cages. Thereafter a bucket of fruit and chow was placed in one of the two smaller cages, and the animals were allowed access to it. The number of pieces of fruit and chow that were taken by each monkey were recorded for $20 \mathrm{~min}$.

\section{Blood and Cerebrospinal Fluid (CSF) Sampling}

Blood and CSF were obtained weekly, on Fridays, while the subjects were anesthetized. To obtain the CSF sam- 
ples, monkeys were captured from their home cages between 12:30 and 13:30 $\mathrm{h}$ and administered general anesthesia (ketamine $\mathrm{HCl} 15.0 \mathrm{ng} / \mathrm{kg}$ ). A 2-ml sample of CSF was removed from the cisterna magna of each subject. CSF samples were quickly frozen in liquid nitrogen. Immediately after the CSF sampling, blood was drawn using vacutainers with EDTA. Six to ten milliliters of blood were drawn from the femoral vein using 22-gauge needles with EDTA vacutainers during each blood draw. Additional blood samples were obtained on the first day of each separation while the subjects were awake using a capture and restraint procedure, 1 and $2 \mathrm{~h}$ after the monkeys were removed from their home cages. The blood samples were centrifuged, and the plasma was frozen and stored with the CSF at $-70^{\circ} \mathrm{C}$. The CSF was analyzed for MHPG, homovanillic acid (HVA), and 5-HIAA concentrations using liquid chromatography with electrochemical detection (Scheinin et al. 1983). Inter- and intraassay variabilities were less than $10 \%$. Plasma samples were assayed for cortisol concentrations by Hazelton Biotechnologies using radioimmunoassays (Abraham et al. 1972). Alcohol was available following the last blood draw. On the remaining 3 days of separation, the animals' behaviors were recorded in the morning, prior to alcohol exposure. Plasma sertraline concentrations were quantified at Pfizer laboratories using the method described by Tremaine (Tremaine and Joerg 1989).

Preclinical studies suggest that the reduction in alcohol consumption by SSRIs such as sertraline is part of a general pattern of overall reduction in food and liquid intake (Lucki et al. 1988; Higgins et al. 1992), and in humans, SSRI treatment sometimes produces weight loss (Naranjo et al. 1989). To assess the possibility that sertraline produced its effects by simply reducing all consummatory behaviors including alcohol intake, daily food intake and weekly weight were recorded in all subjects. Because of the volume of blood obtained, nutrients high in iron were used to supplement the regular diet. Bananas were not provided as a food supplement during the study, because the monkeys consume the peels, which possess high levels of the serotonin precursor tryptophan.

\section{Data Analyses}

Each of the biochemicals, behaviors, and weight were analyzed using weekly means in two-way repeated measures ANOVA, with treatment (medication and placebo) and phase of study (baseline-week 1, baseline-week 2, treatment-week 1 , treatment-week 2 , treatment-week 3 , separation-week 1 , separation-week 2 , reunion-week 1 , and reunion-week 2) as the two independent variables. Alcohol consumption was expressed as weekly means in grams per kilogram of body weight per 1-h session. The animals were further categorized into four high and four low consumers, using a median split of mean alcohol consumption during the baselines, plus the 3 weeks of placebo consumption in the home cage. Alcohol consumption was then analyzed using weekly means in a mixed design three-way ANOVA, with one between-groups factor (alcohol consumption pattern, high or low) and the same two within-group variables (treatment and phase of study). Food consumption was analyzed using chi-square; the dependent variable was the amount of biscuits or fruit eaten each day. The reduced degrees of freedom in the analysis of aggressiveness was due to the fact that social behaviors could be measured only during home-cage interactions. Preliminary analyses showed no sex differences in the monoamines or in alcohol consumption patterns.

\section{RESULTS}

\section{Effect of Sertraline on CSF Monoamine Metabolites and Plasma Hormones}

There was a significant treatment by phase interaction $(F=3.80, d f=8 / 56, p<.003)$, with sertraline reducing CSF 5-HIAA concentrations below baseline during week 1, 2, and 3 of treatment ( $p<.0001$-see Figure 2). Paired comparisons also showed that CSF 5-HIAA concentrations were lower during sertraline than during placebo in weeks $1-3$ of treatment $(p<.01)$. Interestingly, when the social separation stressor was applied, it attenuated the sertraline effect on CSF 5-HIAA concentrations. Whereas the concentrations remained lower than during the baseline, they were not lower than during placebo $(p>.70$ when placebo and sertraline treatment weeks were compared). Moreover, CSF 5-HIAA concentrations during sertraline treatment were not different from placebo during the reunion phase $(p>$ 0.30 ). There was also a nearly significant main effect of sertraline on CSF MHPG concentrations $(F=4.86, d f=$ $1 / 56, p<.07$-see Figure 3), with MHPG concentrations lower during sertraline than during placebo treatment periods. Although the treatment by phase interaction failed to achieve a traditional level of statistical significance $(p<.13)$, paired comparisons showed that from the second week of sertraline, MHPG was lower than during placebo treatment $(p<.02)$. During the first week of social separation, the effect was only approaching significance $(p<.06)$. Similarly, beginning with the second week of sertraline treatment, MHPG concentrations were lower then baseline $(p<.01)$, except for the first week of reunion $(p<.14)$. CSF HVA and plasma cortisol and ACTH concentrations were not affected by sertraline.

\section{Effect of Sertraline on Behavior}

Aggressive and anxiety-like self-directed behaviors were both reduced by sertraline treatment (see Table 1). 


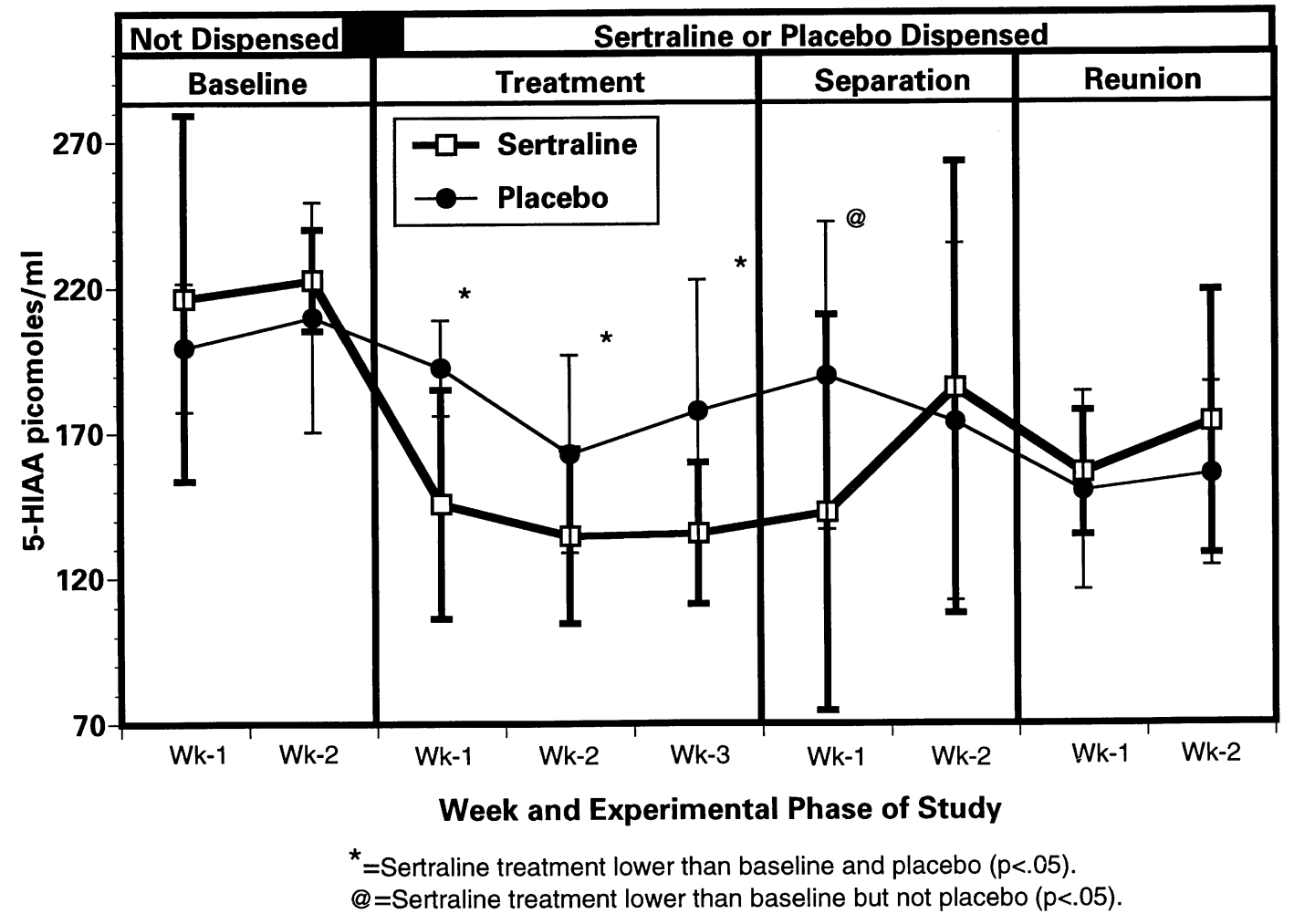

Figure 2. Effect of sertraline on CSF 5-HIAA concentrations. Sertraline reduced CSF 5-HIAA concentrations below placebo during weeks $1-3$ of treatment $(p<.01)$. The social separation stressor attenuated the effect of sertraline on CSF 5-HIAA concentrations (i.e., while the concentrations remained lower than during the baseline, they were not lower than during placebo). CSF 5-HIAA concentrations during sertraline treatment were not different from placebo during the reunion phase. $(\mathrm{Wk}=$ week of the experimental phase.)

For aggression the ANOVA yielded a two-way treatment by week interaction $(F=2.36, d f=6 / 42, p<.05)$, with sertraline reducing aggression across all weeks of treatment relative to the baseline mean. Unexpectedly, beginning the second week of sertraline treatment, the rates of aggression also fell to a rate below baseline in the subjects that were receiving placebo. This may be because the sertraline-treated monkeys failed to respond to the untreated subjects' agonistic cues and as a consequence the nonsertraline-treated subjects had no one with whom to fight. The rates of aggression increased considerably after the separations when the subjects were returned to their home cage (i.e., during reunion), but only among the subjects receiving placebo.

For anxiety-like self-directed behaviors, there was also a two-way treatment by week interaction $(F=2.23$, $d f=8 / 56, p<.04)$, with sertraline reducing the rates of self-directed behaviors below placebo in the second week of treatment, and below baseline and placebo during the third week of treatment $(p<.05)$. Sertraline was ineffective in reducing self-directed behaviors during the social separations, but it reduced the rates of self-directed behaviors below placebo during the post- separation reunion phases $(p<.01)$. None of the other behaviors were affected by sertraline treatment.

\section{Effect of Sertraline on Alcohol Consumption}

Analysis of alcohol consumption showed a treatment by phase interaction $(F=2.22, d f=8 / 48, p<.05)$. There were no baseline differences in alcohol consumption patterns when comparing the medication and nonmedication weeks of the study ( $p>.85)$; thus, all a posteriori comparisons were based on a weighted mean of the 4 weeks of baseline alcohol consumption.

Home Cage, Nonstress. Further analyses showed that sertraline reduced alcohol consumption below baseline beginning during the second week of treatment ( $p<$ .005). The rate of alcohol consumption remained below baseline through the third week of treatment $(p<.004)$. When paired comparisons were performed, there was no difference between the placebo and sertraline treatment conditions for the first 2 weeks of treatment, although the lower mean in treated subjects during week 2 of treatment was nearly significant $(p<.10)$. There 


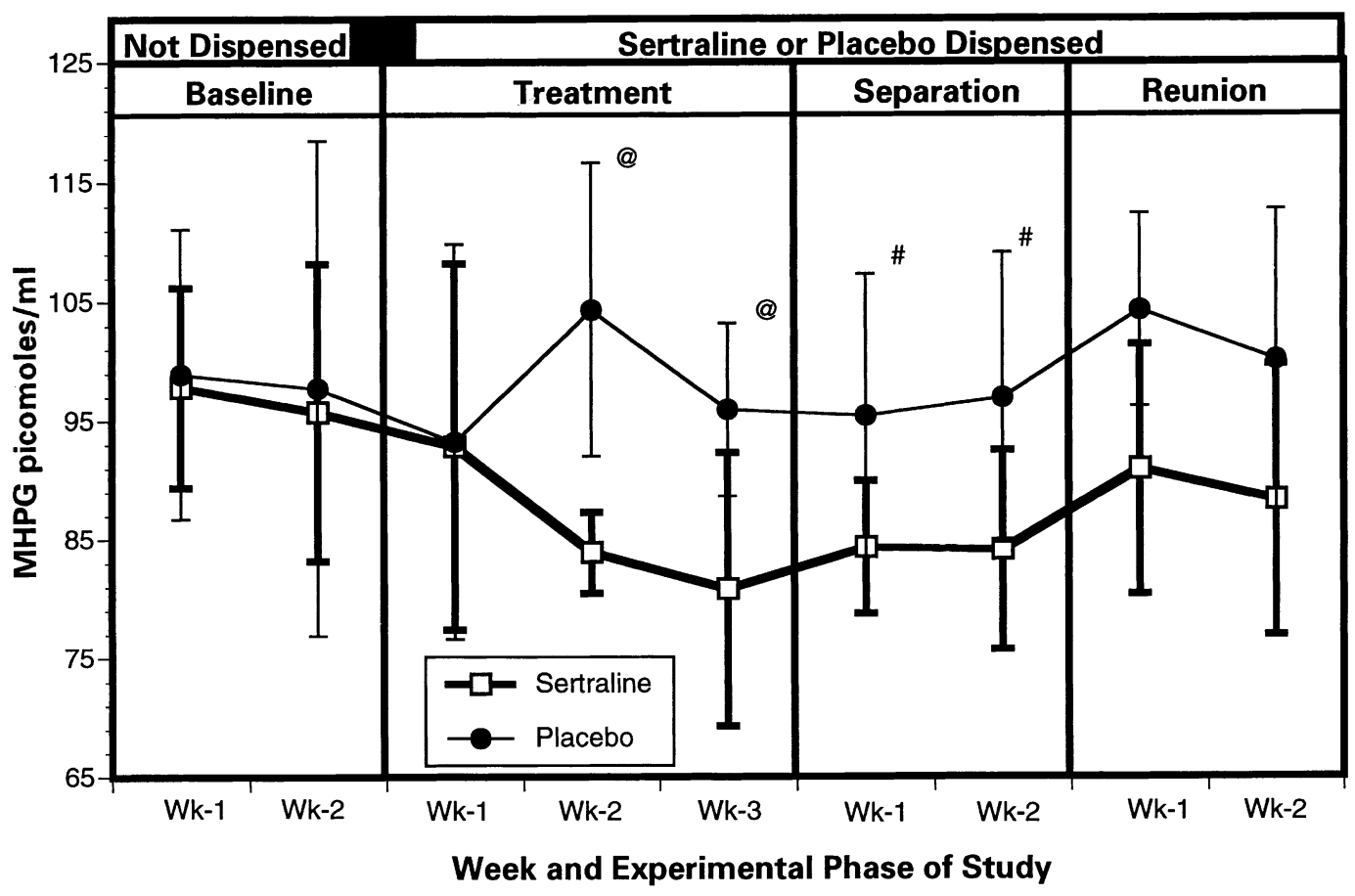

$@=$ Sertraline treatment lower than baseline but not placebo $(p<.05)$.

\#=Sertraline treatment lower than baseline but not placebo $(p<.10)$.

Figure 3. Effects of sertraline on CSF MHPG concentrations. Beginning with the second week of sertraline treatment, MHPG was lower during sertraline treatment than during placebo $(p<.02)$, although during the first week of social separation, the reduction was only of trend-level significance $(p<.06)$. Beginning with the second week of sertraline treatment and continuing throughout the study, MHPG concentrations were lower than baseline $(p<.01)$, except for the first week of reunion $(p<.14)$. The apparent placebo increase in MHPG in the second week of sertraline treatment was not statistically significant when compared to baseline. $\mathrm{Wk}=$ week of the experimental phase.

was, however, a significant difference by week 3 of treatment $(p<.05)$, with subjects consuming more alcohol during the placebo than during the sertraline treatment. This effect of sertraline on consumption was not, however, uniform across individuals $(F=1.83, d f=$ $8.48, p<.09$ ). A priori comparisons of the high and low alcohol consumers across the 3 weeks of medication treatment showed a significant week of treatment effect by alcohol consumption preference (high $(n=4)$ vs. low $(n=4)$ consumption $-F=19.28, d f=2 / 12, p<.0002)$. Further analyses showed that sertraline reduced alcohol consumption only among the high alcohol consumers, with rates of consumption lower beginning during week 2 and continuing during week $3(p<.01$-see Figure 4). Rates of alcohol drinking were unaffected in subjects that consumed low to modest amounts of alcohol when comparisons were made between each of the 3 weeks of home-cage sertraline treatment phases $(p>.35)$.

Separation Stress. When rates of consumption during the first separation were compared to baseline and placebo, sertraline did not reduce alcohol consumption, with rates of consumption during sertraline treatment identical to baseline. By the second separation, how- ever, sertraline reduced alcohol consumption below baseline $(p<.05)$. Further analysis of the 2 weeks of separation showed a week by treatment interaction $(F=21.24, d f=1 / 6, p<.0004)$, with rates of alcohol consumption identical to placebo during the first but not the second separation. During the second separation, rates of alcohol consumption were lower than during placebo $(p<.01)$. There were no differences in the treatment effects between the high and low consumers during the separations.

Home Cage, Reunion Phase. Treatment effects disappeared during the reunion phase $(p>.10)$.

\section{Food Intake and Weight during Treatment}

Neither food intake (biscuits and fruit) nor weight differed across the phases of the study $(p>.30)$.

\section{DISCUSSION}

Of the three monoamine metabolites measured, sertraline had a relatively specific effect on the serotonin sys- 
Table 1. Means \pm Standard Deviations for Aggression and Self-Directed Behaviors

\begin{tabular}{|c|c|c|c|c|c|c|c|c|c|}
\hline & $\begin{array}{l}\text { Base } \\
\text { Wk } 1\end{array}$ & $\begin{array}{l}\text { Base } \\
\text { Wk } 2\end{array}$ & $\begin{array}{l}\text { Treat } \\
\text { Wk } 1\end{array}$ & $\begin{array}{l}\text { Treat } \\
\text { Wk } 2\end{array}$ & $\begin{array}{l}\text { Treat } \\
\text { Wk } 3\end{array}$ & $\begin{array}{c}\text { Sep } \\
\text { Wk } 1\end{array}$ & $\begin{array}{c}\text { Sep } \\
\text { Wk } 2\end{array}$ & $\begin{array}{l}\text { Recov } \\
\text { Wk } 1\end{array}$ & $\begin{array}{l}\text { Recov } \\
\text { Wk } 2\end{array}$ \\
\hline \multicolumn{10}{|l|}{ Rates of Aggression } \\
\hline Sertraline $\mathrm{Mn} / \mathrm{Sd}$ & $2.0 / 2.3$ & $1.96 / 2.6$ & $0.15 / 0.2$ & $0.13 / 0.3$ & $0.08 / 0.1$ & & & $0.14 / 0.2$ & $0.05 / 0.1$ \\
\hline Placebo Mn/Sd & $2.05 / 2.45$ & $2.53 / 3.4$ & $1.26 / 1.4$ & $0.26 / 0.5$ & $0.18 / 0.3$ & & & $2.55 / 2.8$ & $1.58 / 2.4$ \\
\hline \multicolumn{10}{|l|}{ Self Directed } \\
\hline Sertraline Mn/Sd & $66.9 / 49.5$ & $63.5 / 42.6$ & $55.0 / 22.4$ & $44.8 / 27.3$ & $31.1 / 26.4$ & $97.9 / 83.5$ & 112.2/117.6 & $41.4 / 29.7$ & $49.5 / 23.4$ \\
\hline Placebo Mn/Sd & $55.0 / 41.4$ & $64.1 / 40.6$ & $54.5 / 42.1$ & $83.6 / 39.4$ & $55.0 / 28.1$ & $71.9 / 40.9$ & $85.4 / 66.7$ & $87.9 / 41.7$ & $114.1 / 79.9$ \\
\hline
\end{tabular}

$\mathrm{NA}=$ not applicable; Base $=$ baseline phase; Treatment $=$ home-cage treatment phase; Sep $=$ separation phase; Recov $=$ recovery phase. Sertraline or placebo is administered in all phases except baseline. Aggression during social separation cannot be collected, because the animals are alone. Sertraline reduced aggression below baseline during home-cage interactions, and below placebo during the recovery phases. It also reduced selfdirected behaviors below placebo in the second week of treatment, and below baseline and placebo during the third week of treatment. Sertraline also reduced rates of self-directed behaviors below placebo during the postseparation reunion phases. See text for significance levels and statistical probabilities.

tem, reducing CSF 5-HIAA concentrations, while not affecting homovanillic acid, and having a modest effect on MHPG. This finding parallels other studies that have investigated chronic administration of serotonin reuptake inhibitors among nonhuman primates (Raleigh et al. 1986) and humans (Potter et al. 1985). Our findings are consistent with other studies in monkeys and humans that show treatment with an SSRI, while increasing serotonin functioning, reduces CSF 5-HIAA concentrations (Potter et al. 1985; Raleigh et al. 1986). The apparent paradox of sertraline and other reuptake inhibitors reducing CSF 5-HIAA concentrations while increasing synaptic serotonin is a well-documented phenomenon (see, for example, Marsden 1991). Serotonin is largely metabolized into 5-hydroxyindoleacetic acid intraneuronally (Marsden 1991). Reuptake inhibitors increase synaptic serotonin levels and reduce CSF 5-HIAA concentrations by preventing the reuptake of serotonin into the neuron where it can be metabolized. Whereas sertraline's effect is recognized as relatively specific to the serotonin system, these findings are also consistent with studies showing that with repeated administration the SSRIs also reduce CSF MHPG concentrations and presynaptic noradrenergic activity (Rudorfer et al. 1984; Potter et al. 1985; Leonard 1992).

Our hypotheses concerning the effect of sertraline on alcohol consumption and aggression were generally supported. Sertraline reduced alcohol consumption in the subjects whose customary pattern of consumption was excessive to the point of intoxication, while not affecting food intake or weight. This finding is consistent with a growing body of data showing that serotonin reuptake inhibitors reduce alcohol consumption among animals (LeMarquand et al. 1994b) and among some humans who abuse alcohol (LeMarquand et al. 1994a; Pettinati 1996; Tiihonen et al. 1996). It is noteworthy that the reduction in alcohol consumption was limited to subjects whose pattern of consumption was high. Furthermore, there was neither a weight loss nor reduc- tion in food intake, suggesting that the reduction in alcohol consumption was not just an aspect of overall reduced caloric intake.

Although somewhat speculative, one possible explanation for the reduction in alcohol consumption in high consumers is that sertraline improved impulse control, and once subjects began consuming alcohol, they were able to stop drinking before reaching levels of severe intoxication. Animal studies show the importance of normal CNS serotonin functioning for delaying gratification and exhibiting normative impulse control (e.g., see Soubrié 1986 for a review). Clinical studies have also suggested that serotonin-mediated impulse control deficits might underlie alcohol abuse and associated behavioral problems (Linnoila et al. 1993; Stein et al. 1993). Studies of rhesus macaques with low CSF 5-HIAA concentrations show that when they are compared with control subjects, subjects with low CSF 5-HIAA concentrations exhibit impaired impulse control, entering traps more often, engaging more often in physically dangerous behaviors (Mehlman et al. 1994; Higley et al. 1996c), and consuming more alcohol when provided free access (Higley et al. 1996e). In the current study, when mean home cage, nonstress alcohol consumption was correlated with mean CSF 5-HIAA concentrations collected at the same time, there was a negative correlation that approached statistical significance $(r=-0.66$, $p<.08)$.

An alternative, not necessarily mutually exclusive, explanation is that the decrease in alcohol consumption was a consequence of sertraline reducing anxiety. Anxiety is considered a risk factor for alcoholism (Cloninger 1987; Brady and Lydiard 1993). Reduction in anxiety as a mechanism for sertraline's effect is consistent with a study of humans by Brady and colleagues (Brady et al. 1995), showing that sertraline reduces anxiety and alcohol consumption in alcoholics suffering from posttraumatic stress disorder. Indeed, in the present study, during relatively stress-free conditions, sertraline reduced 


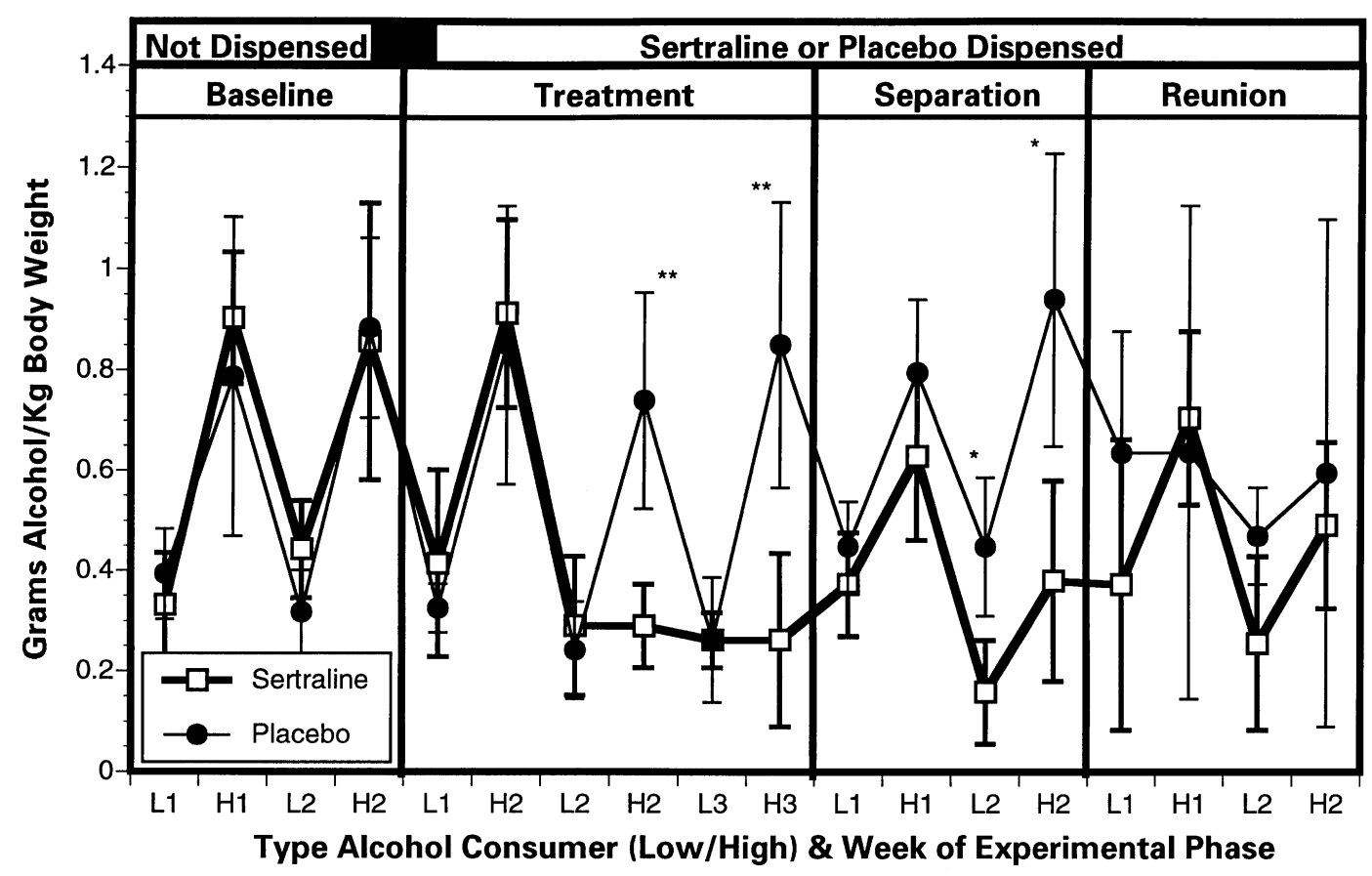

${ }^{\star *}=$ Sertraline treatment lower than placebo $(p<.01)$.

${ }^{*}=$ Sertraline treatment lower than placebo $(p<.05)$.

Figure 4. Effects of sertraline on alcohol consumption. Rates of consumption are plotted as grams of alcohol $/ \mathrm{kg}$ body weight per 1-h session. Sertraline reduced alcohol consumption only among the high alcohol consumers, with lower rates of consumption beginning during week 2 and continuing during week $3(p<.01)$. Rates of alcohol drinking during the 1-h session were unaffected by sertraline in subjects which consumed low to modest amounts of alcohol. The differences in the effect of sertraline on high and low alcohol consumers disappeared during the social separation stress and during reunion. During the social separation, sertraline produced an overall reduction in alcohol consumption with rates of alcohol consumption significantly below baseline by the second separation $(p<.05)$. Sertraline did not affect alcohol consumption during the reunion. $\mathrm{L}=$ low alcohol consumer, $\mathrm{H}=$ high alcohol consumer; Numeral = week of the experimental phase.

both self-directed behaviors, considered a principal measure of anxiety in nonhuman primates (Higley 1985; Capitanio 1986), and alcohol consumption. Furthermore, the reductions in alcohol consumption and self-directed behaviors paralleled each other among the high consumers. This explanation is, however, inadequate by itself, because the high and low consumers exhibited equal rates of self-directed behaviors. Furthermore, sertraline reduced the rate of self-directed behaviors equally in both the high and low consumers.

Sertraline and other SSRIs typically require 14 to 28 days to produce a therapeutic antidepressant response or modify other behaviors such as aggression and irritability (Guy et al. 1986; Kavoussi et al. 1994). Thus it is noteworthy that unlike the primates in this study, in rodents, an immediate reduction in alcohol consumption follows treatment with an SSRI (Gulley et al. 1995). Whether this dissimilarity in time for therapeutic effect is a species or paradigm difference is unknown. In humans, to our knowledge, the time required for therapeutic effect when treating excessive consumption and alcohol abuse has not received systematic study. In one study of inpatient alcohol-dependent males who were allowed access to alcohol each day, researchers found that fluoxetine reduced alcohol consumption during the first week of administration, but not thereafter (Gorelick and Paredes 1992). Other studies have used a more protracted treatment paradigm to test the efficacy of SSRI treatment on alcohol consumption in alcohol-dependent subjects and demonstrated a reduction in consumption both early and late in treatment (Naranjo et al. 1994; Cornelius et al. 1997). The question of how long SSRIs must be administered before they affect alcohol consumption is a research question that requires further study.

The efficacy of sertraline to reduce alcohol consumption was not uniform across all phases of the study. Social stress attenuated the capacity of sertraline to reduce alcohol consumption, with sertraline failing to reduce alcohol consumption under the most stressful conditions during the study. When the subjects underwent the social separation stress, sertraline became temporally ineffective in reducing alcohol consumption and anxiety-like 
behaviors, but its efficacy returned by the second week of the social separation stress, reducing both selfdirected behaviors and alcohol consumption. This return to patterns of high consumption during sertraline treatment amid stressful conditions was even more pronounced during the home-cage reunion phase, when sertraline had no effect on alcohol consumption, even during the second week of home-cage reunion. One possible explanation for sertraline's loss of effectiveness, consistent with our hypotheses, is that stress overrode the pharmacological effects of sertraline. In primates, social stress increases CNS serotonin turnover rate (Bayart et al. 1990). This is particularly true during aggressive encounters (Higley et al. 1996a). Among humans, some studies have shown that high levels of social stress are more likely among alcoholics who relapse than among those who do not relapse (Brown et al. 1990). Moreover, stress-induced relapse of depression during antidepressant treatment has been documented (cf. Leverich et al. 1990: Monroe et al. 1996). Social separation is highly stressful for monkeys, although studies have shown that over repeated social separations, some adaptation to the stress occurs (Higley 1985; Higley et al. 1992c). A pattern of adaptation is consistent with sertraline reducing selfdirected behaviors and alcohol consumption during the second but not the first separation. Although studies have not generally documented the social stress that occurs during home cage reunion for adult and adolescent monkeys, home-cage reunion presents several stressors (Higley 1985). For example, rates of aggression during the reunion are as much as five-fold higher than during the baseline (Higley 1985). The fights are generally used to reestablish dominance ranks within the groups, and in normally reared subjects tend to be brief and more ritualistic than physically damaging. Among peer-reared subjects, however, such fights often lead to escalated and unrestrained aggression, resulting in physical violence (Higley et al. 1994, 1996d). Such high rates of aggression may have been stressful enough to attenuate any protective effects that the sertraline treatment provided to the subjects. To the degree that our findings may be extrapolated to the human condition, this finding has important implications for treatment of alcohol abuse and possibly other syndromes that are treated with monoamine uptake inhibitors. They suggest that relapse may be more likely during stressful periods, but following the stress, the effectiveness of sertraline to reduce alcohol consumption may again return.

The finding that sertraline reduces rates of aggression is consistent with a growing body of preclinical (Higley et al. 1992b, 1994, 1996a,b,c,d; Mehlman et al. 1994, 1995), and clinical data (Brown et al. 1979; Kruesi et al. 1990; Virkkunen et al. 1994a,b) showing that reduced CNS serotonin turnover rate is correlated with high rates of escalated or impulsive aggression, and that increasing CNS serotonin function reduces aggres- sion (Raleigh 1987; Datla et al. 1991; Kavoussi et al. 1994; Raleigh and McGuire 1994). These findings suggest the possibility that sertraline could be used to treat impulsive aggression. It is also of interest, that during the initial home-cage treatment, the subjects who were not on sertraline reduced their rates of aggression, suggesting the possibility that either the aggressive subjects were less likely to provoke aggression in other subjects when they were on sertraline, or that the subjects on sertraline were less likely to respond to aggressive cues from the other monkeys. The apparent aggression reducing effect of placebo for the untreated subjects disappeared during the reunion phase.

\section{SUMMARY AND CONCLUSIONS}

Presumably by increasing CNS serotonin function, sertraline reduced excessive alcohol consumption and aggressiveness. Under conditions of severe stress, sertraline lost its behavioral and biochemical effects, and high rates of alcohol consumption occurred again. To the best of our knowledge, this is the first study in a primate to demonstrate that stress can reverse the biochemical and behavioral effects of an antidepressant.

\section{ACKNOWLEDGMENTS}

All research was carried out according to the NIH Guide for the Care and Use of Laboratory Animals, and under a protocol approved by the institute's Animal Care and Use Committee.

We wish to express our appreciation to Pfizer Laboratories for generously supplying the sertraline used to perform the study, and to Dr. Tremaine at Pfizer who performed the sertraline assays.

\section{REFERENCES}

Abraham GE, Buster JE, Teller RC (1972): Radioimmunoassay of plasma cortisol. Anal Lett 5:757-766

Balldin J, Berggren U, Engel J, Eriksson M, Hård E, Söderpalm B (1994): Effect of citalopram on alcohol intake in heavy drinkers. Alcohol Clin Exp Res 18:1133-1136

Ballenger JC, Goodwin FK, Major LF, Brown GL (1979): Alcohol and central serotonin metabolism in man. Arch Gen Psychiatry 36:224-227

Banki CM (1981): Factors influencing monoamine metabolites and tryptophan in patients with alcohol dependence. J Neural Transm 50:89-101

Bayart F, Hayashi KT, Faull KF, Barchas JD, Levine S (1990): Influence on maternal proximity on behavioral and physiological responses to separation in infant rhesus monkeys (Macaca mulatta). Behav Neurosci 104:98-107

Belsher G, Costello CG (1989): Relapse after recovery from unipolar depression: A critical review. Psychol Bull 104: $84-96$ 
Blomquist AJ, Harlow HF (1961): The infant rhesus monkey program at the University of Wisconsin Primate Laboratory. Proc Animal Care Panel 11:57-64

Borg S, Kvande H, Liljeberg P, Mossberg D, Valverius P (1985): 5-Hydroxyindoleacetic acid in cerebrospinal fluid in alcoholic patients under different clinical conditions. Alcohol 3:415-418

Brady KT, Lydiard RB (1993): The association of alcoholism and anxiety. Psychiatr Q 64:135-149

Brady KT, Sonne SC, Roberts JM (1995): Sertraline treatment of comorbid posttraumatic stress disorder and alcohol dependence. J Clin Psychiatry 56:502-505

Brown GL, Goodwin FK, Ballenger JC, Goyer PF, Major LF (1979): Aggression in humans correlates with cerebrospinal fluid amine metabolites. Psychiatry Res 1:131139

Brown SA, Vik PW, McQuaid JR, Patterson TL, Irwin MR, Grant I (1990): Severity of psychosocial stress and outcome of alcoholism treatment. J Abnorm Psychol 99: 344-348

Brown SA, Irwin M, Schuckit MA (1991): Changes in anxiety among abstinent male alcoholics. J Stud Alcohol 52: $55-61$

Capitanio JP (1986): Behavioral pathology. In Mitchell G, Erwin J (eds), Comparative Primate Biology: Behavior, Conservation and Ecology. New York, Alan R. Liss, pp 411-454

Cloninger CR (1987): Neurogenetic adaptive mechanisms in alcoholism. Science 236:410-416

Cornelius JR, Salloum IM, Ehler JG, Jarrett PJ, Cornelius MD, Black A, Perel JM, Thase ME (1997): Fluoxetine in depressed alcoholics: A double-blind, placebo-controlled trial. Arch Gen Psychiatry 54:700-705

Crowley TJ, Weisbard C, Hydinger-MacDonald MJ (1983): Progress toward initiating and maintaining high-dose alcohol drinking in monkey social groups. J Stud Alcohol 44:569-590

Datla KP, Mitra SK, Bhattacharya SK (1991): Serotonergic modulation of footshock induced aggression in paired rats. Indian J Exp Biol 29:631-635

Economics Medical (1996): Physicians' Desk Reference. Montvale, NJ, Medical Economics

Ervin FR, Palmour RM, Young SN, Guzman-Flores C, Juarez J (1990): Voluntary consumption of beverage alcohol by vervet monkeys: Population screening, descriptive behavior and biochemical measures. Pharmacol Biochem Behav 36:367-373

Erwin J, Drake D, Kassorla E, Deni R (1979): Drinking of ethanol by adult and infant rhesus monkeys (Macaca mulatta). J Stud Alcohol 40:301-306

Gorelick DA (1989): Serotonin uptake blockers and the treatment of alcoholism. Recent Dev Alcohol 7:267-281

Gorelick DA, Paredes A (1992): Effect of fluoxetine on alcohol consumption in male alcoholics. Alcohol Clin Exp Res 16:261-265

Gulley JM, McNamara C, Barbera TJ, Ritz MC, George FR (1995): Selective serotonin reuptake inhibitors: Effects of chronic treatment on ethanol-reinforced behavior in mice. Alcohol 12:177-181
Guy W, Manov G, Wilson WH (1986): Double blind dose determination study of a new antidepressant-Sertraline. Drug Dev Res 9:267-272

Higgins GA, Tomkins DM, Fletcher PJ, Sellers EM (1992): Effect of drugs influencing 5-HT function on ethanol drinking and feeding behaviour in rats: Studies using a drinkometer system. Neurosci Biobehav Rev 16:535-552

Higley JD (1985): Continuity of social separation behaviors in rhesus monkeys from infancy to adolescence. Unpublished doctoral dissertation, University of Wisconsin, Madison

Higley JD, Hasert MF, Suomi SJ, Linnoila M (1991): Nonhuman primate model of alcohol abuse: Effects of early experience, personality, and stress on alcohol consumption. Proc Nat Acad Sci USA 88:7261-7265

Higley JD, Hopkins WD, Thompson WW, Byrne EA, Hirsch RM, Suomi SJ (1992a): Peers as primary attachment sources in yearling rhesus monkeys (Macaca mulatta). Dev Psychol 28:1163-1171

Higley JD, Mehlman P, Taub D, Higley SB, Vickers JH, Suomi SJ, Linnoila M (1992b): Cerebrospinal fluid monoamine and adrenal correlates of aggression in freeranging rhesus monkeys. Arch Gen Psychiatry 49:436441

Higley JD, Suomi SJ, Linnoila M (1992c): A longitudinal assessment of CSF monoamine metabolite and plasma cortisol concentrations in young rhesus monkeys. Biol Psychiatry 32:127-145

Higley JD, Linnoila M, Suomi SJ (1994): Ethological contributions: Experiential and genetic contributions to the expression and inhibition of aggression in primates. In Hersen M, Ammerman RT, Sisson L (eds), Handbook of Aggressive and Destructive Behavior in Psychiatric Patients. New York, Plenum Press, pp 17-32

Higley JD (1996): Primates in alcohol research. Alcohol: Health Res World 19:213-216

Higley JD, King ST, Hasert MF, Champoux M, Suomi SJ, Linnoila M (1996a): Stability of interindividual differences in serotonin function and its relationship to aggressive wounding and competent social behavior in rhesus macaque females. Neuropsychopharmacology 14:67-76

Higley JD, Mehlman PT, Higley SB, Fernald B, Vickers J, Lindell SG, Taub DM, Suomi SJ, Linnoila M (1996b): Excessive mortality in young free-ranging male nonhuman primates with low cerebrospinal fluid 5-hydroxyindoleacetic acid. Arch Gen Psychiatry 53:537-543

Higley JD, Mehlman PT, Poland RE, Taub DT, Vickers J, Suomi SJ, Linnoila M (1996c): CSF testosterone and 5-HIAA correlate with different types of aggressive behaviors. Biol Psychiatry 40:1067-1082

Higley JD, Suomi SJ, Linnoila M (1996d): A nonhuman primate model of type II alcoholism? Part 2. Diminished social competence and excessive aggression correlates with low cerebrospinal fluid 5-hydroxyindoleacetic acid concentrations. Alcohol Clin Exp Res 20:643-650

Higley JD, Suomi SJ, Linnoila M (1996e): A nonhuman primate model of type II excessive alcohol consumption? Part 1. Low cerebrospinal fluid 5-hydroxyindoleacetic acid concentrations and diminished social competence correlate with excessive alcohol consumption. Alcohol Clin Exp Res 20:629-642 
Higley JD, Linnoila M (1997): A nonhuman primate model of excessive alcohol intake: Personality and neurobiological parallels of Type I- and Type II-like alcoholism. Recent Dev Alcohol 13:192-219

Kavoussi RJ, Liu J, Coccaro EF (1994): An open trial of sertraline in personality disordered patients with impulsive aggression. J Clin Psychiatry 55:137-141

Kraemer GW, McKinney WT (1985): Social separation increases alcohol consumption in rhesus monkeys. Psychopharmacology 86:182-189

Kranzler HR, Burleson JA, Korner P, Del Boca FK, Bohn MJ, Brown J, Liebowitz N (1995): Placebo-controlled trial of fluoxetine as an adjunct to relapse prevention in alcoholics. Am J Psychiatry 152:391-397

Kruesi MJ, Rapoport JL, Hamburger S, Hibbs E, Potter WZ, Lenane M, Brown GL (1990): Cerebrospinal fluid monoamine metabolites, aggression, and impulsivity in disruptive behavior disorders of children and adolescents. Arch Gen Psychiatry 47:419-426

LeMarquand D, Pihl RO, Benkelfat C (1994a): Serotonin and alcohol intake, abuse, and dependence: Clinical evidence. Biol Psychiatry 36:326-337

LeMarquand D, Pihl RO, Benkelfat C (1994b): Serotonin and alcohol intake, abuse, and dependence: Findings of animal studies. Biol Psychiatry 36:395-421

Leonard BE (1992): Pharmacological differences of serotonin reuptake inhibitors and possible clinical relevance. Drugs 2:3-9

Leverich GS, Post RM, Rosoff AS (1990): Factors associated with relapse during maintenance treatment of affective disorders. Int Clin Psychopharmacol 5:135-156

Linnoila M, Virkkunen M, George T, Higley D (1993): Impulse control disorders. Int Clin Psychopharmacol 8(Suppl. 1):53-56

Litten RZ, Allen JP, Fertig J (1996): Pharmacotherapies for alcohol problems: A review of research with focus on developments since 1991. Alcohol Clin Exp Res 20:859876

Lucki I, Kreider MS, Simansky KJ (1988): Reduction of feeding behavior by the serotonin uptake inhibitor sertraline. Psychopharmacology (Berlin) 96:289-295

Marsden CA (1991): The neuropharmacology of serotonin in the central nervous system. In Feighner JP, Boyer WF (eds), Selective Serotonin Re-Uptake Inhibitors: The Clinical Use of Citalopram, Fluoxetine, Paroxetine, and Sertraline. New York, John Wiley \& Sons, pp 11-35

Mehlman PT, Higley JD, Faucher I, Lilly AA, Taub DM, Suomi S, Linnoila M (1994): Low CSF 5-HIAA concentrations and severe aggression and impaired impulse control in nonhuman primates. Am J Psychiatry 151: 1485-1491

Mehlman P, Higley JD, Faucher I, Lilly AA, Taub DM, Vickers JH, Suomi S, Linnoila M (1995): Correlation of CSF 5HIAA concentration with sociality and the timing of emigration in free-ranging primates. Am J Psychiatry 152:907-913

Meisch RA, Henningfield JE, Thompson T (1975): Establishment of ethanol as a reinforcer for rhesus monkeys via the oral route: initial results. Adv Exp Med Biol 59:323342
Mello NK, Mendelson JH (1971): The effects of drinking to avoid shock on alcohol intake for primates. In Roach MK, McIsaac WM, Creaven PJ (eds), Biological Aspects of Alcohol. Austin, University of Texas Press, pp 313332

Monroe SM, Roberts JE, Kupfer DJ, Frank E (1996): Life stress and treatment course of recurrent depression: II. Postrecovery associations with attrition, symptom course, and recurrence over 3 years. J Abnorm Psychol 105:313-328

Naranjo CA, Sullivan JT, Kadlec KE, Woodley-Rumus DV, Kennedy G, Sellers EM (1989): Differential effects of viqualine on alcohol intake and other consummatory behaviors. Clin Pharmacol Ther 46:301-309

Naranjo CA, Poulos CX, Bremner KE, Lanctot KL (1994): Fluoxetine attenuates alcohol intake and desire to drink. Int Clin Psychopharmacol 9:163-172

Pettinati HM (1996): Use of serotonin selective pharmacology in the treatment of alcohol dependence. Alcohol Clin Exp Res 20:23A-29A

Potter WZ, Scheinin M, Golden RN, Rudorfer MV, Cowdry RW, Calil HM, Ross RJ, Linnoila M (1985): Selective antidepressants and cerebrospinal fluid. Lack of specificity on norepinephrine and serotonin metabolites. Arch Gen Psychiatry 42:1171-1177

Raleigh MJ, Brammer GL, Ritvo ER, Geller E, McGuire MT, Yuwiler A (1986): Effects of chronic fenfluramine on blood serotonin, cerebrospinal fluid metabolites, and behavior in monkeys. Psychopharmacology 90:503-508

Raleigh MJ (1987): Differential behavioral effects of tryptophan and 5-hydroxytryptophan in vervet monkeys: Influence of catecholaminergic systems. Psychopharmacology 93:44-50

Raleigh MJ, McGuire MT (1994): Serotonin, aggression, and violence in vervet monkeys. In Masters RD, McGuire MT (eds), The Neurotransmitter Revolution. Carbondale, Southern Illinois University Press, pp 129-145

Rudorfer MV, Scheinin M, Karoum F, Ross RJ, Potter WZ, Linnoila M (1984): Reduction of norepinephrine turnover by serotonergic drug in man. Biol Psychiatry 19:179-193

Scheinin M, Chang WH, Kirk KL, Linnoila M (1983): Simultaneous determination of 3-methoxy-4-hydroxyphenylglycol, 5-hydroxyindoleacetic acid, and homovanillic acid in cerebrospinal fluid with high-performance liquid chromatography using electrochemical detection. Anal Biochem 131:246-253

Sellers EM, Higgins GA, Tompkins DM, Romach MK (1992): Serotonin and alcohol drinking NIDA Res Monogr 119:141-145

Soubrié P (1986): Reconciling the role of central serotonin neurons in human and animal behavior. Behav Brain Sci 9:319-364

Stein DJ, Hollander E, Liebowitz MR (1993): Neurobiology of impulsivity and the impulse control disorders. J Neuropsychiatry Clin Neurosci 5:9-17

Tiihonen J, Ryynanen OP, Kauhanen J, Hakola HP, Salaspuro M (1996): Citalopram in the treatment of alcoholism: a double-blind placebo-controlled study. Pharmacopsychiatry 29:27-29 
Tremaine LM, Joerg EA (1989): Automated gas chromatographic electron capture assay for the selective serotonin uptake blocker sertraline. J Chromatography 496:423-429

Virkkunen M, Kallio E, Rawlings R, Tokola R, Poland RE, Guidotti A, Nemeroff C, Bissette G, Kalogeras K, Karonen SL, Linnoila M (1994a): Personality profiles and state aggressiveness in Finnish alcoholic, violent offenders, fire setters, and healthy volunteers. Arch Gen Psychiatry 51:28-33

Virkkunen M, Rawlings R, Tokola R, Poland RE, Guidotti A, Nemeroff C, Bissette G, Kalogeras K, Karonen SL, Linnoila M (1994b): CSF biochemistries, glucose metabolism, and diurnal activity rhythms in alcoholic, violent offenders, fire setters, and healthy volunteers. Arch Gen Psychiatry 51:20-27 